\title{
Development trend and application prospect of $3 d$ printing technology in the intelligent manufacturing
}

\begin{abstract}
The development of 3D printing technology is one of the signs known as the third industrial revolution. And it is the combination of industrial development and the development of artificial intelligence, which greatly promoted the development of modern manufacturing technology and control technology. In the future, the precision, intelligent and convenient, universal and stable operation of the 3D printer will become the future industrialization research focus and development trend.
\end{abstract}

Keywords: 3D printing technology, development trend, application prospect
Volume 4 Issue I - 2018

Yang Tang, Haifeng Chen

School of Mechatronic Engineering, Southwest Petroleum University, China

Correspondence: Yang Tang, School of Mechatronic Engineering, Southwest Petroleum University, China, Email tangyanggreat@I26.com

Received: August 19,2017| Published: January 31, 2018

\section{The development trend of $3 \mathrm{~d}$ printing technology}

In the backdrop of the big data and the information era, the 3D printers with single-step and single mechanized can't adapt to the needs of the era development. ${ }^{1}$ With the application of 3D printers, there is a larger demand for the development of the technology, which is mainly manifested about the more stringent requirements for the operation of $3 \mathrm{D}$ printers and the physical quality of printing. Therefore, combining the control technology of 3D printer with big data, improving its informatization and intelligentization will become the new trend of 3D printing technology development.

\section{Elaboration}

With the higher requirements of the manufacturing process, improvement of the accuracy of 3D printers is its inevitable trend. ${ }^{2}$ Because alternating nozzle print, printing by material combining, and printing large parts are the application direction of 3D printing, the physical properties of the surface and internal for print out the components will have higher requirements. ${ }^{3}$ These have benefited from the high precision of $3 \mathrm{D}$ printing technology, which is the guarantee of 3D printing technology directly for finished product manufacturing and parts production.

\section{Intelligence and convenience}

As we all known, there are many working procedures in the 3D printing process, including software design, post-processing, optimization of software control, conversion of different materials, removal of components, internal bubbles, and supporting material after molding. ${ }^{4}$ The realization of the above process requires the support of programmed intelligent equipment. Although the current 3D printing equipment has a higher degree of automation, more intelligent and more convenient will be protection for the further promotion and application of the future $3 \mathrm{D}$ printing technology.

\section{Generalization}

"Generalization" of the 3D printer, on the one hand, it means that
$3 \mathrm{D}$ printers are becoming more and more popular. On the other hand, it means "one machine with multiple uses". ${ }^{5}$ The $3 \mathrm{D}$ printer is used as the external output device of the computer, which can approach each user and printed the conceptual model of relevant software design by user into a three-dimensional entity. Different printing materials can be used to print parts to adapt to different application scenarios; it can save equipment replacement and maintenance costs. ${ }^{6}$ The $3 \mathrm{D}$ printing service has become the new trend of industry development and has wide application prospect and great commercial value.

\section{Stabilization}

The stabilization includes controlling stability and running stability. With the development of industry, the application of industrial 3D printers will surely play an important role. ${ }^{7}$ In the industry, the disturbance factor is complex, which will inevitably have higher requirements for the stability of the industrial 3D printer. ${ }^{8}$ Improvement of control stability is to optimize 3D printer's controller algorithm, including the application of classical algorithm and artificial intelligence algorithm in $3 \mathrm{D}$ printer. The improvement of running stability refers to the optimization of control technical indexes, including overshoot in control parameters, lag time constant, steady-state error, etc.

\section{Application prospect of $3 d$ printing technology}

3D printing technology will have a wide range of applications in the future, including equipment manufacturing, material research and development or processing, software design, service provide and so on. ${ }^{9}$ If its application and demand are not keeping up, the development of the technology will be limited. The application of 3D printing technology will have a profound impact on traditional manufacturing industry, including the following aspects:

a. Firstly, making the manufacturing model undergoing profound changes. More traditional manufacturing technology with the method of reduction of material processing, the biggest drawback of the model is raw material waste is serious, 3D printing technology has changed the processing mode, which can save 
material, shorten processing time, and increase efficiency of industrial production. ${ }^{10}$

b. Secondly, promote the rapid development of production technology. 3D printing is an integrated application of embedded system, computer aided design, material science, laser, control, network, material science and many other science and high technology and new technology. ${ }^{11}$ The use of 3D printing is the transformation of the high and new technology from theory to realize the practice.

c. Thirdly, revolutionize will be done for the business model $3 \mathrm{D}$ printing can make product production go personalized and customized, which will shorten the life cycle of products to market. Its advantage is that through the Internet, it can quickly establish efficient supply chain, market sales and user service network. This business model can achieve agile manufacturing and elite manufacturing.

d. Fourthly, the development of Artificial Intelligence (AI) will be promoted. ${ }^{12}$ As a new concept in the $21^{\text {st }}$ century, AI has begun to integrate into the public life. The combination of intelligent products such as the Internet of things, robots, smart homes and 3D printers has become a new trend, 3D printing to change traditional manufacturing industries, which will improve the sharing of technology. These innovations will feed back to old technologies and promote the creation of new technologies for 3D printing and artificial intelligence.

\section{Conclusion}

The 3D printing technology is a milestone in the development of manufacturing technology. It is a sign that people have made great progress in industrial manufacturing. Along with the continuous renewal of 3D printing technology, the technology can be more and more near people's horizons, the high cost of product manufacturing obstacles will be eased, people will no longer passively wait for, but according to their own innovation actively to realize fast, thus create a popular innovation. 3D printing technology in the application of business and services, leading to production model, business model, competition model, etc. A big change that promote the production of "customization" business model, derive some new subdivision industries, guide the new economic development, improve people's quality of life, provide more high quality life service to people.

\section{Acknowledgments}

None.

\section{Conflicts of interest}

None.

\section{References}

1. Moriana M Garcia, Kevin Messner, RichardJ Urban, et al. 3D Technologies: New tools for information scientist stoen gage, educate and empower communities. Proc Am Soc Info SciTech. 2015 .

2. Sebastian Hällgren, Lars Pejryd, Jens Ekengren. 3D Data Export for Additive Manufacturing-Improving Geometric Accuracy. Procedia CIRP. 2016;50:518-523.

3. Izabela Hager, Anna Golonka, Roman Putanowicz. 3D Printing of Buildings and Building Components as the Future of Sustainable Construction? Procedia Engineering. 2016;151:292-299.

4. Kim FH, Moylan SP, Garboczi EJ, et al. Investigation of pore structure in cobalt chrome additively manufactured parts using Xray computed tomography and three-dimensional image analysis. Additive Manufacturing. 2017;17:23-38.

5. Kareli Brans. 3D Printing, a Maturing Technology. IFAC Proceedings. 2013;46(7):468-472.

6. Guannan $\mathrm{Xu}$, Yuchen $\mathrm{Wu}$, Tim Minshall, et al. Exploring innovation ecosystems across science, technology, and business: A case of 3D printing in China. Technological Forecasting \& Social Change. 2017.

7. David Bak. Rapid prototyping or rapid production? 3D printing processes move industry towards the latter. Assembly Automation. 2003;23(4):340-345.

8. Jin Huang, Ji Feng Wang, Cheng Zhi Yang. The Steady State Precision Control of DC Servo Motor Based on State Space Adaptive Pole Assignment. Applied Mechanics and Materials. 2013;2549(345):68-71

9. Helen Rogers, Norbert Baricz, Kulwant S Pawar. 3D printing services: classification, supply chain implications and research agenda. International Journal of Physical Distribution \& Logistics Management. 2016;46(10):886-907.

10. Jian Yuan Lee, Wen See Tan, Jia An, et al. The potential to enhance membrane module design with 3D printing technology. Journal of Membrane Science. 2016;499:480-490.

11. Rui Zou, Yang Xia, Shiyi Liu, et al. Isotropic and anisotropic elasticity and yielding of 3D printed material. Composites Part B: Engineering. 2016;99:506-513.

12. Liu Juyan. Changing manufacturing rules for $3 \mathrm{D}$ printers. World science. 2012;7:22-24. 